\title{
ASSET MARKETS AND EQUILIBRIUM SELECTION IN PUBLIC GOODS GAMES WITH PROVISION POINTS: AN EXPERIMENTAL STUDY
}

\author{
Bruno Broseta, Enrique Fatás, Tibor Neugebauer"
}

WP-AD 2001-29

\begin{abstract}
Correspondence to E. Fatás: LINEEX, Universidad de Valencia, Campus Tarongers, 46022 Valencia (Spain). Fatas@uv.es..

Editor: Instituto Valenciano de Investigaciones Económicas, S.A.

First Edition November 2001

Depósito Legal: V-4663-2001
\end{abstract}

Ivie working papers offer in advance the results of economic research under way in order to encourage a discussion process before sending them to scientific journals for their final publication.

\footnotetext{
* The authors gratefully acknowledge the financial support provided by the Vice President for Research's Small Grants Program at the University of Arizona (FRS-466477), Project PB98-1051-C02-02 of the Spanish Ministry of Education and Culture, the Valencia Institute for Economic Research (Ivie) 2000 Research Grant and Project GV98-08-2960 of the Valencia Regional Government. The authors thank Nikos Georgantzis, Jordi Brandts, Susan Laury, Rob Moir, Gonzalo Olcina, Giovanni Ponti, Arthur Schram, Rachel Croson and seminar participants at Amsterdam, Paris, Magdeburg, Castellon and Valencia for helpful comments.

** B. Broseta: Organismo Público Valenciano de Investigación (OPVI) and LINEEX; E. Fatás: LINEEX and University of Valencia; T. Neugebauer: University of York and LINEEX.
} 


\title{
ASSET MARKETS AND EQUILIBRIUM SELECTION IN PUBLIC GOODS \\ GAMES WITH PROVISION POINTS: AN EXPERIMENTAL STUDY
}

\author{
Bruno Broseta, Enrique Fatás and Tibor Neugebauer
}

\begin{abstract}
A B S T R A C T
In this paper we report some experimental results on the effects that auctioning the right to play a public goods game with a provision point may have on equilibrium selection and efficiency. A control treatment reveals that, as in the experimental literature for similar environments, subjects' behavior converges to the inefficient outcome whenever they are endowed with the right to play the game. However, auctioning off such a right among a larger population of players has a significant efficiency-enhancing effect. Once the Pareto-dominant equilibrium in the second stage is reached, the auction price at the first stage increases to its upper limit, dissipating all players' gains associated with the provision of the public good. The full contribution equilibrium was extremely robust: individual subjects' deviations from the equilibrium strategy were not able to force lower market prices and did not affect provision of the public good in subsequent periods.
\end{abstract}

KEYWORDS: Public Goods; Provision Points; Experimental Markets. 


\section{INTRODUCTION}

Public good provision is a fundamental source of market failure, since the nonexcludability property of such a good makes it possible to consume it for free, once it is supplied. Thus, in the familiar voluntary contribution mechanism (henceforth VCM) model, free-riding (i.e., zero contribution) is a dominant strategy and the resulting equilibrium is socially sub-optimal. The introduction of provision points eliminates the strict dominance of free-riding and generates a multiplicity of pure strategy equilibria, which, when symmetric, are Pareto-ranked.

In the experimental literature on the standard $\mathrm{VCM}^{1}$ different mechanisms have been studied to favor higher voluntary contributions and, eventually, reach efficient outcomes. Isaac, McCue and Plott (1985) found evidence for higher provision levels of a public good due to higher marginal per capita returns (MPCR). Repetition, on the other hand, was found to induce an increase in free riding behavior. Isaac and Walker (1988) showed that face-to-face communication might be effective in producing efficient allocations of the public good in repeated play; and that even after communication ceased in subsequent repetitions, a high provision level may still be sustained. Isaac and Walker (1991) reported that costly face-toface communication also enhanced the voluntary contribution to the public good.

The introduction of provision points also seems to enhance contribution levels. In the seminal work of Isaac, Schmidtz and Walker (1989) the introduction of provision points proved to enhance voluntary contribution to the public good, although the provision point was, in fact, almost never reached in absence of a money back guarantee ${ }^{2}$. Interestingly enough, if the public good was not provided in the initial periods decay in contributions followed, suggesting convergence of subjects' choices to the inefficient outcome.

The effects of institutional changes in the rule of the game on the efficiency of the resulting equilibrium outcomes have also been analyzed in the experimental literature. Isaac, Schmidtz and Walker (1989)'s Experimental Design II and Bagnoli and McKee (1991) found additional evidence of the contribution enhancing effect of provision points in the presence of a money back guarantee. Marks and Croson (1998) studied the positive effect of rebate rules while Croson and Marks (1999) found no significant differences in the rate of successful provision with incomplete information about other subjects' valuations of the public good.

\footnotetext{
${ }^{1}$ See Davis and Holt (1993) and Ledyard (1995) for a review of the experimental literature on public goods games.

${ }^{2}$ In the case of a money back guarantee, any endowment subjects contribute to the public good is refunded (as if they had invested in the individual exchange) if the provision point is not obtained.
} 
Finally, Cadsby and Maynes (1999) found that continuity in group contributions, higher rewards, and higher thresholds in the presence of money back guarantees also encourage public good provision.

Very similar issues have been analyzed -both by experimentalists and by theorists- in the context of coordination games in which the existence of multiple and, usually, Paretoranked Nash equilibria pose both coordination and efficiency problems. In particular, the influence that strategic uncertainty -or players' uncertainty about each others' choices- might have on the efficiency of coordination outcomes has been studied experimentally by Van Huyck, Battalio and Beil (henceforth, "VHBB") (1990,1991) and analyzed among others, by Crawford (1995) and Broseta (2000). Almost simultaneously, a growing body of experimental evidence (Cooper et al. (1992a, 1992b), Cachon and Camerer (1996), VHBB (1993)) focused on how preplay communication may improve the efficiency of coordination outcomes. In particular, in VHBB (1993)'s remarkable experimental designs, the right to play a coordination game was auctioned off amongst the subjects, yielding powerful and systematic gains in the efficiency of coordination outcomes with respect to the environment in which the players were directly endowed with the right to play and identical coordination game.

In this paper, the contribution enhancing effect of implicit pre-play communication of this kind in a public goods game with a threshold is at issue. In particular, we exploit the structural similarities existing between a VCM with provision points and some coordination games in which strategic uncertainty plays an important role in equilibrium selection (like those analized in VHBB $(1990,1991))$ to test, using experimental methods, whether the introduction of a competitive market can increase subjects' contributions and, eventually, yield an efficient provision level for the public good. In this sense, our work can be seen as an extension, and thus as an indirect test of the robustness, of VHBB (1993)'s market driven, efficiency-enhancing mechanism to the provision of public goods with provision points. Following Van Huyck, Battalio and Beil (1993), an asset market is implemented by means of an English clock multiple-unit auction, in which prices signal subjects' willingness to play a public good game in the second stage. Our experimental results for a control treatment show that, when subjects are endowed with the right to play the VCM with a Provision Point, the efficient equilibrium -full provision of the public good- obtains in only 3 out of 12 experimental runs. In all the remaining sessions ( 9 out of 12 experiments), the dynamics were consistent with the previous experimental results for similar environments ${ }^{3}$ : initial (average) group contributions may amount up to $75-80 \%$ of the provision level, only to decline progressively as the game is repeated. By period 20, the last in our experimental design, less

\footnotetext{
${ }^{3}$ See, for example, Isaac et al. (1989) or Cadsby and Maynes (1999).
} 
than one subject on average was playing his/her efficient equilibrium strategy in 8 out of the 9 runs in which play appeared to converge towards the inefficient equilibrium.

The results for this same environment when the right to play is auctioned off among a larger group of players are remarkably different. First of all, the results suggest that subjects' play converged towards the efficient equilibrium in 7 out of 12 experiments, including 3 runs in which the outcomes for the initial periods were inefficient. In only one case did the dynamics converge to the inefficient equilibrium in which the public good was not provided. Thus, the introduction of a game form auction as a first stage appears to significantly affect equilibrium selection in the VCM with a provision point, as compared with the control treatment.

The evolution of the market prices subjects had to pay to enter the VCM-PP is also noteworthy. In the initial periods, market prices for all 12 experiments were always at -or above- the payoff that any individual player could obtain from the inefficient outcome but also, with few exceptions, below the payoff a subject playing the VCM in the second stage could obtain from the efficient, full provision equilibrium. Clearly, subjects playing the latter equilibrium might profit from such a situation in the two-stage game, while disequilibrium behavior would imply zero (or even negative) payoffs. As the number of repetitions increased, however, market prices tended to rise until players' surplus was, in the efficient equilibrium, zero or negligible ${ }^{4}$. Finally, we also observed that the competitive pressures induced by the first stage game also resulted in that the efficient outcome of the VCM was, when reached, extremely robust to individual deviations from the equilibrium strategy.

The remainder of the paper is organized as follows: in Section 2 we briefly discuss the class of environments analyzed in the rest of the paper. Section 3 presents the experimental design. The experimental results are reported in Section 4. Section 5 provides our concluding remarks.

\section{GENERAL FRAMEWORK: THE VCM WITH PROVISION POINTS}

We consider the following standard, symmetric VCM with a provision point and discrete contribution levels. Each member of a group of $n$ agents, receives an initial endowment $e_{i}=e(i=1, \ldots, n)$ and is asked to privately (and simultaneously) allocate it

\footnotetext{
${ }^{4}$ Subjects' payoffs in the two-stage game also tended to 0 when behavior converged to the inefficient equilibrium of the second stage, VCM game.
} 
between a contribution $c_{i} \in\{0, . ., e\}$ to the provision of a public good and a remainder, $e-c_{i}$, to be contributed to a private exchange. Letting $C=\sum_{i=1}^{n} c_{i}$, we denote the provision point of the game by $C^{*} \in(0 ; \bar{C}]$, where $\bar{C}=n e$. Then, player $i$ 's payoff function is given by:

$$
\pi_{i}\left(c_{i}, c_{-i}\right)= \begin{cases}a\left(e_{i}-c_{i}\right)+\frac{1}{n} G\left(C^{*}\right), & C \geq C^{*} \\ a\left(e_{i}-c_{i}\right), & C<C^{*}\end{cases}
$$

where $c_{-i}$ denotes the vector of contributions for all players but $i$, and $a>0$ and $\frac{1}{n} G(C)$ denote the rates of return of a unit contribution to the private and public exchanges respectively. As usual, $G^{\prime}()>$.$a and the marginal per capita return (henceforth MPCR) is given by$ $\frac{G^{\prime}(.)}{a n} \in(0 ; 1)$.

The structure of the set of Nash equilibria for this game depends on the value of the threshold $C^{*}$; in all cases, however, there is a multiplicity of pure-strategy Nash equilibria. In what follows we concentrate our analysis on the case of $C^{*}=\bar{C}$ ("High Provision Point"). In this case, the game (denoted as VCM-HPP) has only two symmetric (and strictly Paretoranked) pure strategy equilibria in which $c_{i}=e$ and $c_{i}=0$ for all $i$ respectively, and no purestrategy asymmetric equilibria ${ }^{5}$.

There is a substantial structural similarity between the VCM-HPP game described here and a well-known coordination game, the Stag-Hunt Game, which suggests that strategic uncertainty may play a key role in equilibrium selection in this type of environment. To see why, consider the simplified (all or nothing) VCM-HPP in which $c_{i}=\{0 ; e\}$ for all $i$, with payoffs given by (1), and with $C^{*}=\bar{C}$. This game has two strict - and Pareto-ranked - Nash equilibria, in which $c_{i}=e$ (the efficient equilibrium, with individual payoffs $\Pi_{i}(e, \ldots, e)=\bar{\Pi}$ ) and $c_{i}=0$ (with payoffs $\Pi_{i}(0, \ldots, 0)=e$ ) for all $i=1, \ldots, n$ and $\bar{\Pi}>e$. Even though there are no incentive problems to sustain the efficient equilibrium, the players do face a non-trivial coordination problem because this type of environment pits collective rationality (or efficiency) against individual players' risk of lower payoffs associated with their uncertainty about each other's choices, or strategic uncertainty. In the presence of strategic uncertainty, an individually rational player will weight the higher payoff of choosing (in equilibrium) the

\footnotetext{
${ }^{5}$ The game has no asymmetric equilibria because any contribution level $c_{i}$ such that $0<c_{i}<e$ is strictly dominated by contributing $c_{i}=0$. We will often use this property below -when analyzing equilibria of the VCMHPP- so as to simplify the discussion by considering only 'all or nothing' contribution levels $c_{i} \in\{0, e\}$.
} 
highest contribution level, $c_{i}=e$, with payoff $\bar{\Pi}=\frac{G(\bar{C})}{n}$, with the risk of a lower payoff -in fact, a payoff of 0 - when a single player shirks and contributes $0^{6}$. In other words, players' strategies are optimal only when they are based on identical beliefs about how the game will be played.

Isaac, Schmidtz and Walker (1989)'s Experimental Design I analyzed this type of VCM-HPP, referring to the influence strategic uncertainty might have on subjects' behavior as "the assurance problem". The following general features of their results are noteworthy. First, the initial group contribution levels were significantly positive, well above the 0-level implied by the inefficient equilibrium but, with one exception ${ }^{7}$, were below the provision point and thus insufficient to insure provision of the public good. Second, group contributions decayed -relatively fast-, so that behavior appeared to converge to the inefficient equilibrium: in the last two periods (out of a total of 10), the group contribution was 0 in 5 out of 6 experiments. From these data, Isaac et al. (1989) concluded that the assurance problem better described the patterns of equilibrium selection they observed in the VCM-HPP.

This experimental evidence, coupled with the structural similarities between the VCM-HPP and the Stag-Hunt Game discussed above, suggest that strategic uncertainty may play an important role in equilibrium selection in the former type of environment. The profound impact that strategic uncertainty may have on the emergence of inefficient outcomes in games with multiple, Pareto-ranked Nash equilibria has been studied by Crawford (1995) and Broseta (2000) for the class of experimental coordination games in Van Huyck, Battalio and Beil (1990, 1991). Following a related line of research, a growing body of experimental literature has focused on how different (implicit) preplay communication mechanisms and institutions may, often along the lines of forward-induction type of arguments, alleviate the effects of strategic uncertainty and increase the efficiency of coordination outcomes.

Cooper, De Jong, Forsythe and Ross (1992a) observed that in a 2-person Stag-Hunt Game experiment, the inefficient, secure strategy obtained in 325 out of 330 plays. However, coordination on the Pareto-dominant equilibrium was enhanced considerably through oneway communication and achieved, $97 \%$ of the time, by means of two-way communication. In an extension of this work, Cooper et al. (1992b) implemented an outside option which, once foregone by (some of) the players would, under the logic of forward induction, induce the efficient equilibrium. Their experimental results showed that this particular form of implicit pre-play communication may help the subjects to reach the efficient equilibrium in a 2-person

\footnotetext{
${ }^{6}$ Note that a player can insure himself a payoff of $e$ by not contributing at all.

${ }^{7}$ In one experiment (out of six) the subjects locked-in the efficient equilibrium starting from period 2 on.
} 
Stag-Hunt game more frequently than explicit one-way communication; nevertheless, twoway communication still produced even better results.

Cachon and Camerer (1996) retake two of VHBB's (1990, 1991) environments -the large-group minimum game and the median game- and analyze the effects that charging entry fees to the players before playing the coordination game may have on efficiency. In their "Must Play" treatment, all subjects are charged a commonly known fee to play the game. In their "Opt Out" treatment, the entry fee was also publicly announced but players were given the chance to opt out, avoid paying the cost and receive a zero payoff for that round ${ }^{8}$. They found that the efficiency of coordination increased for the median game in both treatments, while only the Opt Out design was effective in this sense in the minimum Game.

Finally, VHBB's (1993) remarkable experimental results show how competition for the right to play may greatly enhance efficiency in a class of coordination games they had considered in their earlier 1991 paper. More precisely, VHBB designed a 2 stage (repeated) game in which the right to play the n-person coordination game was auctioned off among a larger population of players in the first stage of the game. The results could then be compared with those of their 1991 designs, in which the same number of subjects were simply endowed with the right to play an identical coordination game. The results were striking: when the game was played without auctions, behavior in all experiments converged to inefficient equilibrium outcomes. When the right to play was auctioned off among the players, the subjects bid up -without exception- the market-clearing price to a level recoverable only in the efficient equilibrium, and then converged to that equilibrium. As Crawford and Broseta (1998) suggest, this experiment suggests a potentially important new way in which competition may improve efficiency; but it also seems reasonable to test the robustness of the efficiency-enhancing mechanism designed by VHBB in environments beyond those that directly generalize their 1993 experimental designs.

This paper is an attempt to do so, extending VHBB's (1993) designs to the provision of public goods and, in particular, to the VCM-HPP game described above. We now discuss our experimental designs.

\footnotetext{
${ }^{8}$ Note that in both treatments, losses are possible (even in equilibrium) whenever the entry fee is set higher than the lowest-paying equilibrium payoff.
} 


\section{EXPERIMENTAL DESIGN}

We conducted two experimental treatments. The purpose of the control treatment was to established a baseline for the Voluntary Contribution Mechanism with a Provision Point (VCM-HPP), in which the subjects are endowed with the right to play the public goods game. In the second treatment we introduce the Two-Stage VCM-HPP (TS-VCM-HPP), in which the right to play the game is, at the first stage of the game, auctioned off amongst a larger population of players using, as in VHBB (1993), an ascending bid English Clock Auction.

\subsection{The control treatment.}

We set $n=4, e=40$ and $a=1$ in the standard VCM-HPP described in section 2, with all payoffs expressed in experimental currency units $(\mathrm{ECU})^{9}$. The payoff from contributing to the public good is chosen as $G\left(C^{*}\right)=2.5 \times C^{*}$ (so that the MPCR is 0.625), and $C^{*}=n e=160$. Each experiment consisted of the same group of 4 subjects, interacting independently and anonymously for twenty periods. Hence, in every period of the VCM-HPP, the four subjects had an initial endowment of 40 ECU and would decide how much to contribute to the provision of the public good, with individual contributions restricted to the set $\{0 ; 10 ; 20 ; 30 ; 40\}$ ECU. The public good is provided only if each subject contributes her or his total endowment of 40 ECU. Therefore, individual subjects' equilibrium payoffs are 40 ECU's in the inefficient equilibrium and 100 ECU's in the efficient outcome, in which the threshold is reached and full provision occurs. Otherwise, any subject's payoff will be the difference between the initial endowment, $e$, and her/his contribution.

The resulting payoff list ,as shown to the experimental subjects, is the following:

Figure 1. Payoff matrix in the public goods game with provision point

\begin{tabular}{|c|c|c|c|c|c|c|c|c|c|c|c|c|c|c|c|c|c|c|}
\hline \multirow{7}{*}{$\begin{array}{l}\text { Individual } \\
\text { contribution }\end{array}$} & \multicolumn{18}{|c|}{ GROUP CONTRIBUTION } \\
\hline & & 0 & 10 & 20 & 30 & 40 & 50 & 60 & 70 & 80 & 90 & 100 & 110 & 120 & 130 & 140 & 150 & 160 \\
\hline & 0 & 40 & 40 & 40 & 40 & 40 & 40 & 40 & 40 & 40 & 40 & 40 & 40 & 40 & & & & \\
\hline & 10 & & 30 & 30 & 30 & 30 & 30 & 30 & 30 & 30 & 30 & 30 & 30 & 30 & 30 & & & \\
\hline & 20 & & & 20 & 20 & 20 & 20 & 20 & 20 & 20 & 20 & 20 & 20 & 20 & 20 & 20 & & \\
\hline & 30 & & & & 10 & 10 & 10 & 10 & 10 & 10 & 10 & 10 & 10 & 10 & 10 & 10 & 10 & \\
\hline & 40 & & & & & 0 & 0 & 0 & 0 & 0 & 0 & 0 & 0 & 0 & 0 & 0 & 0 & 100 \\
\hline
\end{tabular}

\footnotetext{
${ }^{9}$ The exchange rate was $1 \mathrm{ECU}=2$ ptas in the standard VCM; and $1 \mathrm{ECU}=8$ ptas in the two-stage game. In the experimental treatment with the two-stage game, subjects were given an initial capital balance of 200 ECU. Possible losses they would make were remitted.
} 
We conducted 3 sessions of the control treatment, each of which consisted of four groups of four subjects interacting at the same time. The subjects were randomly paired for the duration of the experiment, were not able to figure out who their partners were, and members of the same group never sat next to each other.

Common information was established by reading instructions out loud and using an overhead projector to display the software interface (see Figures 5 and 6 in the Appendix). During the experiments, all the subjects received the following information through their computer terminals: after each round, each player was informed about his/her group contribution to the public good, his/her individual contribution and his/her individual payoff for that round. In addition, all the subjects had unrestricted access, at all times, to the history of these variables -together with each player's cumulative payoff- for all previous rounds.

We also screened our experimental subjects in order to insure comprehension of the rules of the game and of the software interface. From the population of potential subjects who showed up for the experiment, 16 were chosen to participate in each session, according to the following procedures: at the end of the introductory session, in which the instructions were read aloud and the software was explained, participants had to fill in a brief questionnaire (see Appendix). The sixteen who performed best in the test (we randomized in case of ties) were brought to the laboratory where they were randomly assigned to computer terminals; the others were asked to leave, and were paid the show up fee ${ }^{10}$.

\subsection{Second Treatment: The Two-Stage Game.}

In our second treatment, the right to play the same VCM-HPP as described above was auctioned among a larger subject pool. In other words, at this first stage, $N>n$ players are given the opportunity to purchase in an asset market the right to participate in the second stage, so that only $n$ players are selected to play the second stage VCM-HPP. The other $N-n$ players exit the game (and are not allowed to re-enter the auction until the following period), and receive a payoff of zero for that round. As in VHBB (1993), the asset market consists of an English-clock multiple unit auction which, in our case, was run on the computer (see the interface in the Appendix III). The auction clock starts at an initial (non-negative) price and is successively increased at regular time intervals. The current bid price is publicly announced (so that it is common information), and players simultaneously decide whether to bid the price in order to (possibly) enter the second stage or to exit the auction. The clock stops when at most $n$ players are willing to pay the current price, so that the winners are the $n$ players who

\footnotetext{
${ }^{10}$ Whether they participated or not, subjects were all paid a show-up fee of 750 pesetas (about US\$ 5) which included 250 ptas for the participation in the test.
} 
longest stay in the auction. The last bid price at which at most $n$ players remain in the auction determines the cost that the $n$ winners in the auction have to incur to enter the second stage of the game. If more than $n$ players bid the maximum price, or if at the time the clock is stopped less than $n$ players continue in the auction, the $n$ winners are determined randomly, as detailed below.

The auction mechanism was implemented as follows. In any given experiment, the initial population was set to $\mathrm{N}=8$, while $\mathrm{n}=4$ as in the control treatment. The starting bid was 5 ECU's less than the payoff in the lowest-paying equilibrium in the VCM-HPP (i.e., 35 ECU). Every 5 seconds the current price was raised, up to a maximum of 100 ECU's. Price increments were set equal to 5 ECU's until either two subjects, out of the initial eight, had exited the auction or until a price of 95 ECU's was reached, at which point they were lowered to $1 \mathrm{ECU}^{11}$. At each stage of the auction, the subjects were asked to confirm their willingness to pay the announced price or to exit ${ }^{12}$. Once they had exited, they were not able to enter again and had to wait until the following period. The auction stopped either $i$ ) if four or less subjects remained in it, or ii) if the price had reached its maximum. In the first case, if exactly four subjects had confirmed to bid the latest announced price, they entered immediately the second stage; if less bidders remained, the quota was completed randomly with additional subjects from those who exited at the last price. In the second case, the four subjects to enter the second stage were selected at random among those who had confirmed to pay the maximum price. In any case, the market price to be paid for entering the second stage game was fixed at the ultimate bid held by at least four bidders.

We conducted 6 sessions, with two groups of eight subjects each, so that the available data for the TS-VCM-HPP include 12 experiments. In each experiment, the two-stage game was repeated 20 times. The experimental procedures were identical to those in the control treatment, with the following exceptions. First, the quiz used to screen the subjects included some questions on the auction mechanism. Second, the information available to the subjects in each auction round included the current price, the number of active bidders in the auction and the final market price (see the software interface in the Appendix III); for those subjects who entered the VCM-HPP at the second stage, the same information as in the control treatment was available for the current round; similarly, the history of all past outcomes and individual payoffs was also available to all subjects.

\footnotetext{
${ }^{11}$ In our first two sessions (experiments TS-VCM-HPP 1-4), price increments were also 1 ECU after only 6 subjects remained in the auction, but were not automatically lowered from 5 ECU to 1 ECU after a price of 95 was reached. Price resolution was increased as noted in the text for all remaining experiments.

${ }^{12}$ The instructions specified that, by default, if a subject did not enter his/her decision within the specified time period ( 5 seconds) he/she would be assumed to remain in the auction.
} 
All experiments were conducted in the laboratory at the University of Valencia $(\text { LINEEX })^{13}$. Subjects were recruited among undergraduate students of economics and business at the University of Valencia through posted, public advertisements. They were all inexperienced in that they had not participated previously in public goods or auction experiments; for most of them it was the first experiment at all. A total of 144 students participated in the experiments reported here, all of them only once. No communication in any way between subjects was permitted during the course of a session. One session of the control treatment took approximately one hour, while about two hours were needed to run the TS-VCM-HPP treatment. By participating in these experiments, subjects earned an average of 2500 pesetas (US\$15), in addition to the show-up fee.

\section{EXPERIMENTAL RESULTS}

\subsection{The control treatme nt (VCM-HPP): Results.}

The results for the 12 experiments (with 20 rounds each) of the control treatment, in which subjects were endowed with the right to play the VCM-HPP, are summarized in Figure 2. Table 1, in Appendix I, includes the raw data, together with some aggregate statistics of interest.

Subjects' behavior in the initial rounds of the control treatment is consistent with previous research (see, for example, Isaac et al. (1989)): in period 1, the average group contribution reaches $81 \%$ of the level required to provide the public good, while the inefficient equilibrium outcome is never observed. To the contrary, the efficient equilibrium is attained in 3 out of 12 experiments (respectively 3,5 and 12), while a group contribution of 150 (given the players' strategy basis, the closest possible outcome to the provision of the public good) occurs in two additional ones (experiments 4 and 6).

Our data also reveal some interesting features about the dynamics of players' choices ${ }^{14}$. First, individual contribution levels clearly decline across time (with the exceptions noted below) and, using some caution given that data on only 20 periods are available, behavior appears to converge to the inefficient outcome, also as in the related literature. From period 10 onwards, the modal strategy choice is zero contribution to the public exchange. And, by period 20, the average group contribution (excluding experiments 5, 10 and 12 in which behavior converges to the efficient outcome) is 33.3 , approximately $21 \%$ of the level

\footnotetext{
13 The software was programmed by means of Abbink and Sadrieh (1995)'s RatImage@, Version 3.30.

${ }^{14}$ For the trajectory of average contributions a Spearman rank correlation coefficient of -0.86 can be calculated. Thus, the hypothesis of time independence of average contributions is strongly rejected $\left(\mathrm{p}<10^{-5}, \mathrm{t}=-7.1\right)$.
} 
Figure 2. Group contribution in VCM-HPP experiments
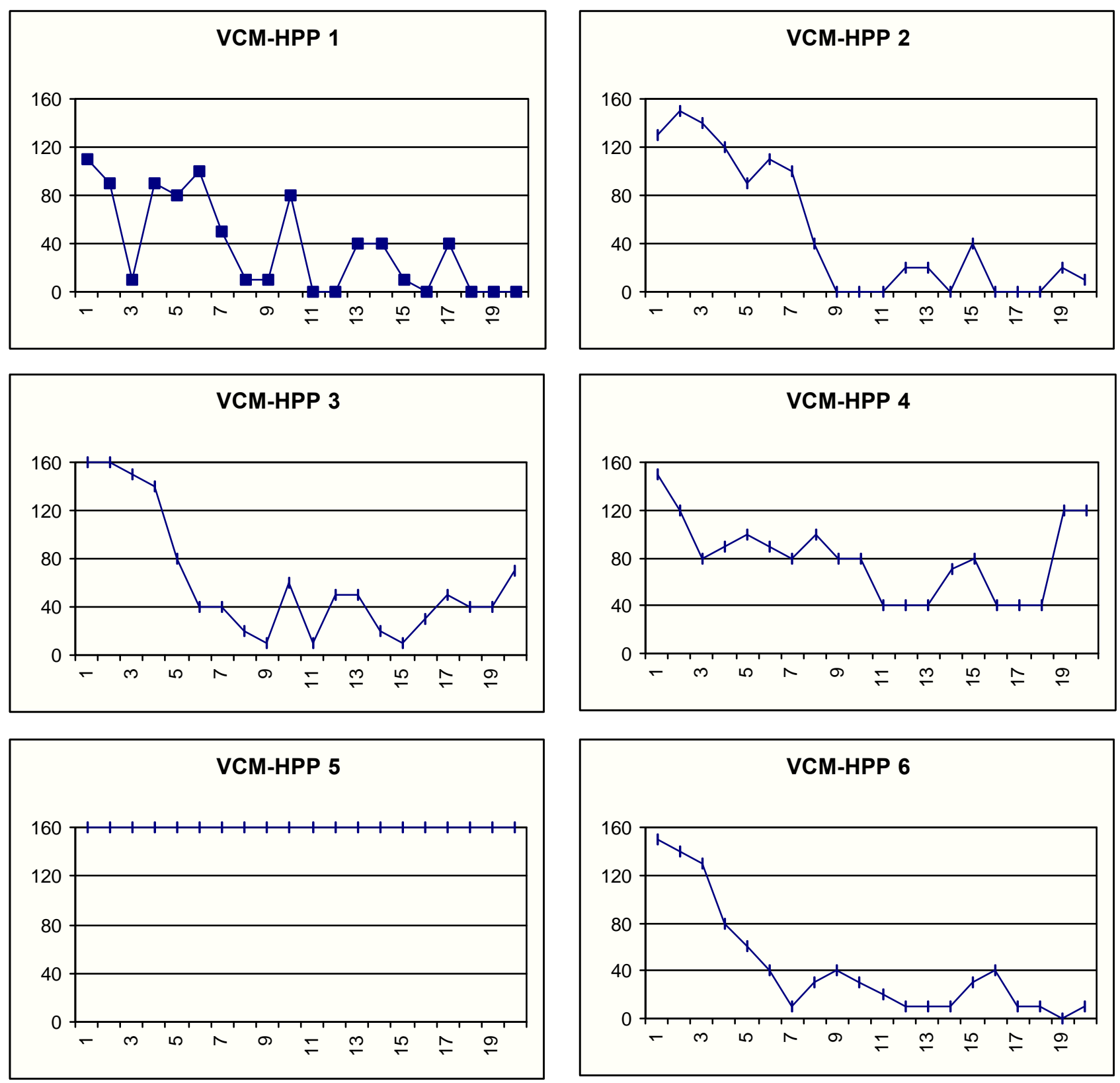
Figure 2. Group contribution in VCM-HPP experiments (continued)
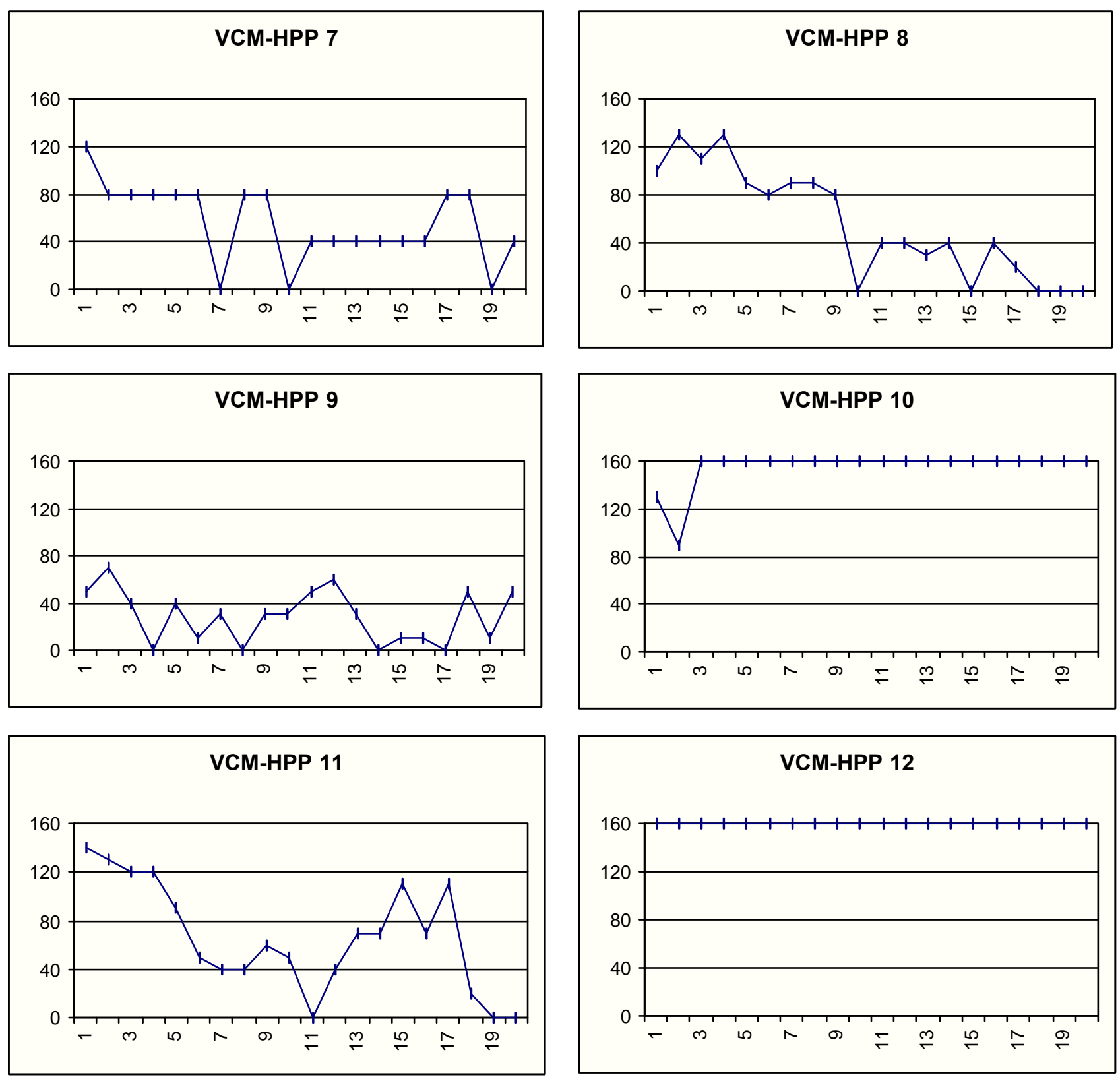
required to reach provision of the public good. Second, of the experiments 3, 5 and 12 in which subjects locked-in the efficient outcome in the initial periods, only the latter two exhibit some stability; the dynamics of experiment 3 reveal the instability of the efficient outcome to unilateral deviations of subjects' equilibrium strategies: one subject deviates only once, and the group is never able to coordinate again. On the other hand, Session 10 is also noteworthy in that subjects are able to coordinate on the efficient equilibrium even though the outcome for the first two periods is inefficient.

\subsection{The Two-Stage VCM-HPP Treatment (TS-VCM-HPP): Experimental Results.}

In the TS-VCM-HPP, the right to play the same VCM-HPP as in the control treatment is, at the first stage, auctioned off amongst a population of 8 subjects. This two-stage-game is, also as in the control treatment, repeated for twenty periods.

The data on group contributions and market-clearing prices for all 12 experiments (where $\mathrm{P}$ and $\mathrm{G}$ denote Price and Group contribution in each session) are summarized graphically in Figure 3, while Table 2 in Appendix I contains more detailed information. Before looking at the experimental data in detail, we focus on Figure 4 which shows the evolution of the average group contribution to the public good in both the control and the twostage treatments (denoted as VCM-12 and TS-VCM-12, respectively). Notice that, in each treatment, the levels of the average group contributions are affected by the occurrence of both the efficient and inefficient equilibria of the VCM-HPP; hence, whether the dynamics of the average group contribution in, say, the control treatment tend to a value of 0 (i.e., the inefficient equilibrium) is obscured by the existence of 3 experiments (respectively 5, 10 and 12) in which the efficient outcome prevailed. Hence we include, also in Figure 4, two additional measures of average group contributions to the public good: in the first (VCM-9), for the control treatment, we exclude experiments 5, 10 and 12 so as to include all experiments but those in which the efficient outcome prevailed. Similarly, for the TS-VCMHPP treatment, we report the average group contribution across experiments, excluding experiment 12 (and labeled TS-VCM-11 in Figure 4), in which subjects' behavior converged towards the inefficient equilibrium. In the end, a simple look at Figure 4 reveals that auctioning the right to play the VCM-HPP has a noticeable effect, significantly increasing the level of group contributions with respect to the control treatment. Checking the efficiencyenhancing effect of the auction mechanism, however, requires a comparison between the relative frequencies of the efficient and inefficient outcomes in both treatments. 
Figure 3. Group contribution and auction market prices in TS-VCM-HPP experiments
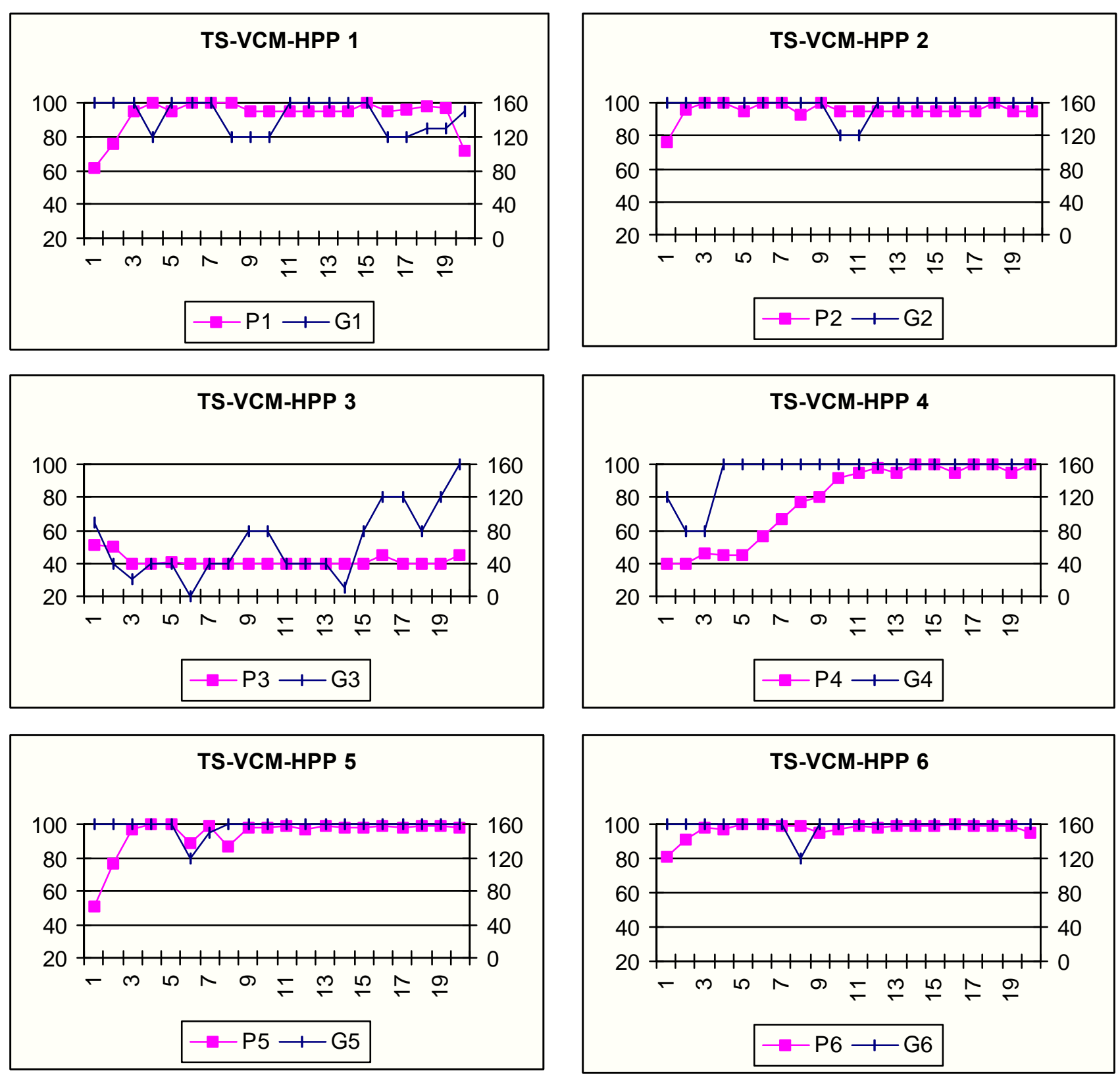
Figure 3. Group contribution and auction market prices in TS-VCM-HPP experiments (continued)
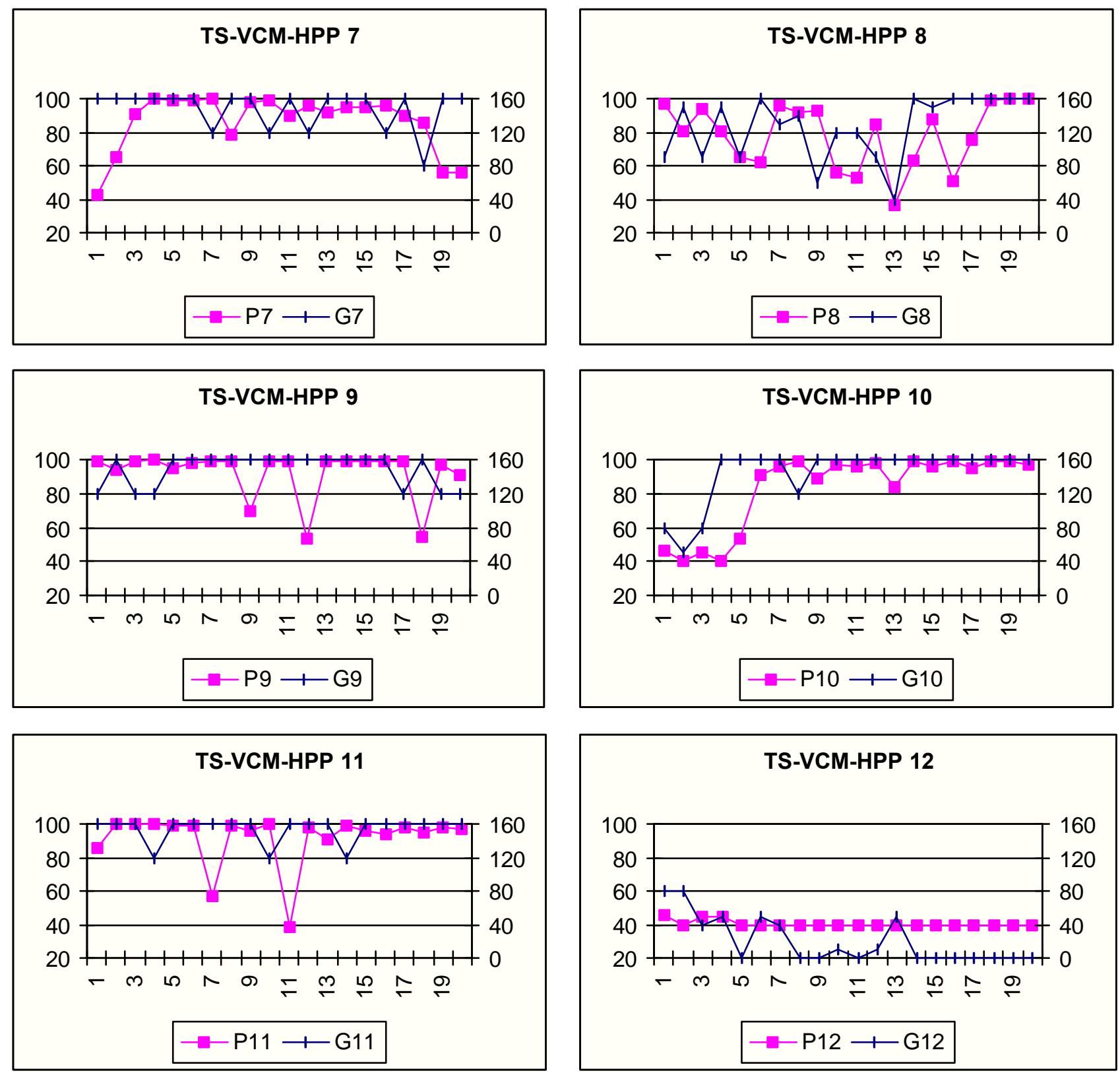
Figure 4. Average Group Contributions in VCM and TS

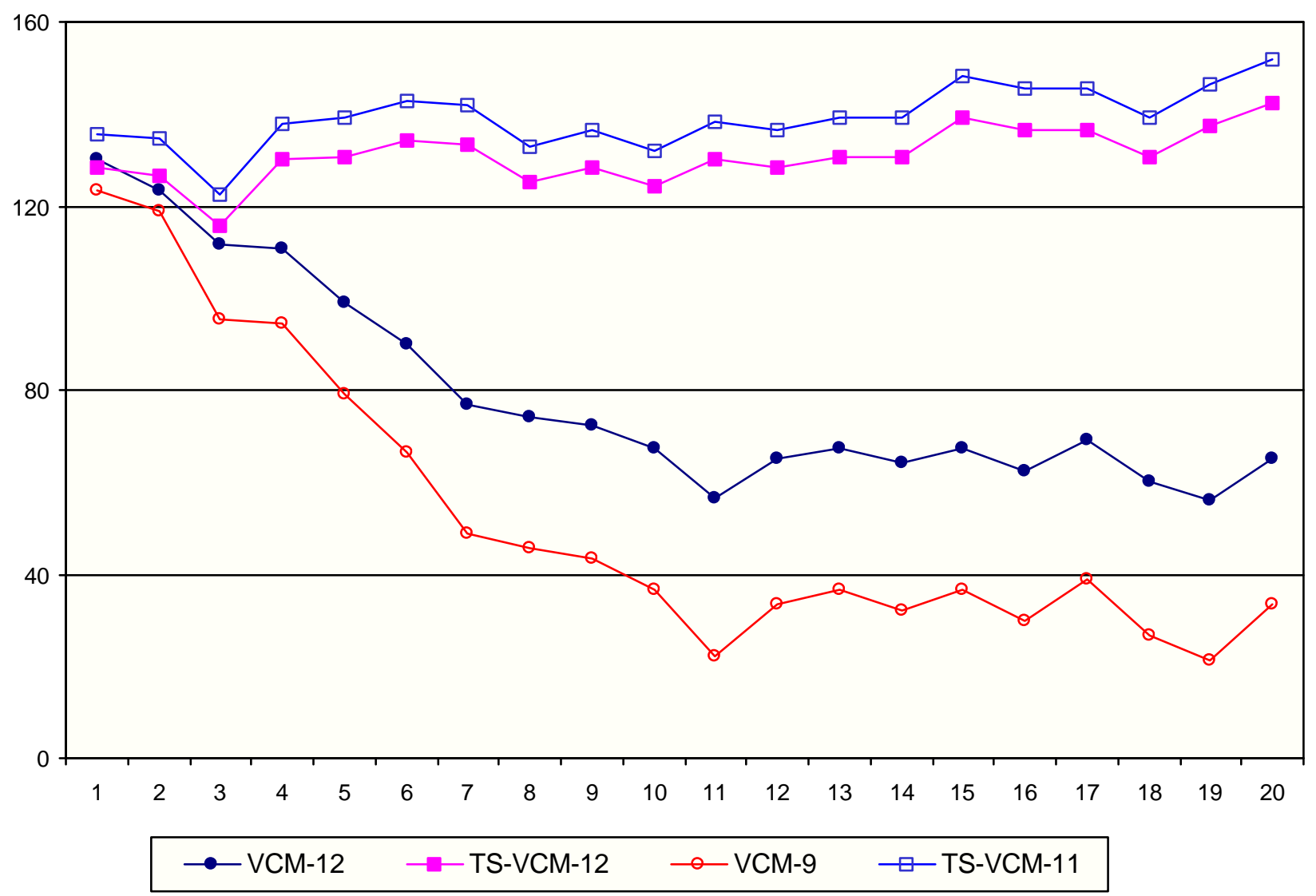


Figure 3 reports market prices, expressed in the same units as individual players' payoffs, and the group contribution for all twenty periods in experiments 1 to 12 . Even though the null hypothesis of stochastic equivalence of initial group (and individual) contributions in the TS-VCM-HPP and the VCM-HPP is not rejected by a one-tailed Mann-Whitney test, we note that in the period 1 the provision point is attained 6 out of 12 times (experiments 1, 2, 5, 6, 7 and 11), twice as much as in the control treatment. However, and for standard significance levels, the alternative hypothesis of higher contributions in the TS-VCM-HPP is supported for periods 5 and $20^{15}$. Allover, the relative frequencies of strategies $\{40,30,20$, $10,0\}$ are $\{0.8,0.01,0.01,0.02,0.16\}$ in the TS-VCM-HPP and in the VCM-HPP $\{0.44$, $0.03,0.03,0.07,0.43\}$ respectively, so that contributions in the TS-VCM-HPP dominate stochastically those in the VCM-HPP.

With respect to subjects' equilibrium behavior in the second stage VCM-HPP, the data reveal that the efficient outcome is reached, by period 20, in 9 out of 12 experiments versus 3 in the control treatment. A stronger impression still, because it suggests convergence to equilibrium behavior in the VCM-HPP, is conveyed by Sessions 2, 4, 5, 6, 8, 10 and 11 in which subjects' behavior locks in the efficient equilibrium from period 15 onwards; as Figure 3 reveals, in 3 out of these 7 cases the outcomes in initial periods were inefficient.

What does the evolution of the market-clearing prices reveal? With few exceptions (e.g., experiment 4) the initial market prices are always above 40 ECU's; in these conditions, it is a strictly dominated strategy in the second stage game for any player to choose any other contribution level than his/her full endowment of 40 ECU's so that, in equilibrium, the efficient outcome should arise. In fact, and whenever the market price is between 40 and 100 ECU's, the winners of the auction can obtain positive payoffs by coordinating on the full provision equilibrium. This can be seen from the data (Figure 3 and Table 2 in Appendix I), which suggest that in most experiments in which convergence to the efficient equilibrium occurs (e.g., experiments 2, 4, 5, 6, 8, 10 and 11), subjects are able to coordinate before prices have reached their maximum. However, as the number of repetitions and the competitive pressures associated with the auction mechanism increase, prices quickly tend to rise until they reach their maximum, 100 ECU's, and all subjects's surplus from playing the efficient equilibrium is dissipated. This fact, that market prices increase successively to reach the maximum payoff in the second stage game, replicates one of the strongest results in VHBB's (1993) experiments with coordination games.

\footnotetext{
${ }^{15}$ The Mann-Whitney test yields a p-value of $\mathrm{p}<.0326(.00001)$ in the $5^{\text {th }}\left(20^{\text {th }}\right)$ period. In addition, for the trajectory of average contributions the Spearman rank correlation coefficient is +0.72 . Thus, the hypothesis of time independence of average contributions is also rejected $(\mathrm{p}<.00031, \mathrm{t}=4.4)$.
} 
Some interesting patterns of individual behavior also emerge from the data. As we have already discussed in Section 2, the efficient equilibrium in the VCM-HPP is highly unstable in that a unilateral deviation of the equilibrium by a single agent, even if it is costly for him/her, can determine the outcome of the game and thus, have potentially significant payoff implications for the other players ${ }^{16}$. Our data suggest that some players might use such (costly) punishment devices, mostly in situations in which the efficient equilibrium in the VCM-HPP prevails and the market price is close to 100 (so that the surplus from entering the second stage of the game is zero or negligible), possibly in order to punish other members in the group and force lower market prices in subsequent rounds. Such defections from the efficient equilibrium are observed, for example, in experiments 2 (periods 10 and 11), 6 (period 8), 7, 9 (period 17), 10 (period 8) and 11 (period 10). Nevertheless, such costly attempts to push market prices down usually have only transitory effects since the latter tend, due to competitive pressures, to recover quickly afterwards.

Finally, it is important to note that subjects' behavior in experiment 12 clearly converged to the inefficient outcome of the VCM-HPP while the market-clearing price quickly converged to 40 ECU's. As expected, subjects' payoffs in the second stage game were also dissipated by the price they had to pay to enter, so that their surplus was, in equilibrium, equal to zero.

\section{CONCLUSION}

We have studied, using experimental methods, equilibrium selection in a class of public good games, the VCM with a provision point. The previous experimental literature on this type of environment concludes that, even though initial contribution levels tend to be relatively high, the efficient outcome -the only one in which the public good is provided- is rarely observed, and that the dynamics of players' choices tend, as the game is repeated, towards the inefficient outcome. These "stylized facts" are, indeed, replicated in our control treatment.

We exploit, in the paper, the structural similarities between the VCM-HPP and some coordination games with multiple, Pareto-ranked Nash equilibria in which strategic uncertainty plays a crucial role in the inefficiency of the resulting coordination outcomes. In particular, we extend VHBB (1993) approach and investigate whether the introduction of a

\footnotetext{
${ }^{16}$ This was not the case in VHBB (1993) environments, because the median is considerably more robust to unilateral deviations, so that a single player's ability to affect the outcome is considerably reduced.
} 
competitive market used to auction the right to play the public good game can, in fact, promote efficiency in a VCM-HPP type of environment.

Our results show that, indeed, auctioning the right to play has a significant efficiencyenhancing effect in that it improves the subjects' ability to coordinate on the Pareto-dominant outcome. Our results for the two stage game also show that, whenever the efficient equilibrium was attained in the VCM-HPP, all payoffs from the public goods game were completely dissipated at the first stage because the price paid by the subjects for the right to play quickly reached its maximum level, an individual player's payoff in the efficient equilibrium. Second, the dynamics in the data suggest that, contrary to what is observed when the players are endowed with the right to play the VCM-HPP (as in our control treatment), the competitive pressures induced by the auction market were enough to make the efficient equilibrium extremely robust to subjects' unilateral deviations from their equilibrium strategy profile.

Our experimental results suggest the convenience of, at least, two additional lines of research. The first is to study the dynamics of players' choices, both theoretically and empirically, in order to learn more (hopefully, within a unified model) about the mechanisms underlying equilibrium selection both in the VCM-HPP and in the TS-VCM-HPP. The learning models in Crawford (1995) and Broseta (2000), which have already proved themselves useful to understand behavior in coordination games in the presence of strategic uncertainty, might also be a good starting point for the class of environments studied here. Second, it may be worthwhile to conduct further experiments in order to check the robustness of the market driven, efficiency-enhancing mechanism we have introduced in this paper to changes in the particular VCM-HPP structure used here. More precisely, the introduction of "intermediate" provision points -in which the provision point is reached without all the players having to contribute their full endowments- generates additional, asymmetric equilibria which, often, are not Pareto-ranked. Whether the introduction of auction mechanisms -or of other forms of implicit preplay communication- may help subjects to coordinate in this kind of environment remains an open question. 


\section{APPENDIX I:}

Table 1. Data for the VCM-HPP: individual contributions of total endowment; group contribution $[0 ; 160]$; individual zero contributions; mean group contribution

\begin{tabular}{|c|c|c|c|c|c|c|c|c|c|c|c|c|c|c|c|c|c|c|c|c|}
\hline \multirow{3}{*}{$\begin{array}{l}\text { Experiment } \\
\text { VCM-HPP } 1\end{array}$} & \multicolumn{20}{|c|}{ Period } \\
\hline & \multirow[t]{2}{*}{1} & \multirow[t]{2}{*}{2} & \multirow[t]{2}{*}{3} & \multirow[t]{2}{*}{4} & \multirow[t]{2}{*}{5} & \multirow[t]{2}{*}{6} & \multirow[t]{2}{*}{7} & \multirow[t]{2}{*}{8} & \multirow[t]{2}{*}{9} & \multirow[t]{2}{*}{10} & \multirow[t]{2}{*}{11} & \multirow[t]{2}{*}{12} & \multirow[t]{2}{*}{13} & \multirow[t]{2}{*}{14} & \multirow[t]{2}{*}{15} & \multirow[t]{2}{*}{16} & 17 & 18 & 19 & 20 \\
\hline & & & & & & & & & & & & & & & & & & & & \\
\hline$\#\left(c_{i}=40\right)$ & 2 & 1 & 0 & 2 & 2 & 2 & 1 & 0 & 0 & 2 & $0 *$ & $0 *$ & 1 & 1 & 0 & $0 *$ & 1 & $0^{*}$ & $0^{*}$ & $0^{*}$ \\
\hline$\sum \mathrm{c}_{\mathrm{i}}$ & 110 & 90 & 10 & 90 & 80 & 100 & 50 & 10 & 10 & 80 & 0 & 0 & 40 & 40 & 10 & 0 & 40 & 0 & 0 & 0 \\
\hline VCM-HPP 2 & & & & & & & & & & & & & & & & & & & & \\
\hline$\#\left(c_{i}=40\right)$ & 3 & 3 & 3 & 3 & 2 & 2 & 2 & 1 & $0^{*}$ & $0 *$ & $0 *$ & 0 & 0 & $0 *$ & 1 & $0^{*}$ & $0 *$ & $0^{*}$ & 0 & 0 \\
\hline$\sum \mathrm{c}_{\mathrm{i}}$ & 130 & 150 & 140 & 120 & 90 & 110 & 100 & 40 & 0 & 0 & 0 & 20 & 20 & 0 & 40 & 0 & 0 & 0 & 20 & 10 \\
\hline VCM-HPP 3 & & & & & & & & & & & & & & & & & & & & \\
\hline$\#\left(c_{i}=40\right)$ & $4 *$ & $4 *$ & 3 & 3 & 2 & 0 & 1 & 0 & 0 & 1 & 0 & 1 & 1 & 0 & 0 & 0 & 0 & 0 & 0 & 1 \\
\hline$\sum \mathrm{c}_{\mathrm{i}}$ & 160 & 160 & 150 & 140 & 80 & 40 & 40 & 20 & 10 & 60 & 10 & 50 & 50 & 20 & 10 & 30 & 50 & 40 & 40 & 70 \\
\hline VCM-HPP & & & & & & & & & & & & & & & & & & & & \\
\hline$\#\left(c_{i}=40\right)$ & 3 & 3 & 2 & 2 & 2 & 1 & 1 & 1 & 2 & 2 & 1 & 1 & 1 & 1 & 2 & 1 & 1 & 1 & 3 & 3 \\
\hline$\sum \mathrm{c}_{\mathrm{i}}$ & 150 & 120 & 80 & 90 & 100 & 90 & 80 & 100 & 80 & 80 & 40 & 40 & 40 & 70 & 80 & 40 & 40 & 40 & 120 & 120 \\
\hline VCM-HPP 5 & & & & & & & & & & & & & & & & & & & & \\
\hline$\#\left(c_{i}=40\right)$ & $4 *$ & $4 *$ & $4^{*}$ & $4^{*}$ & $4^{*}$ & $4 *$ & $4^{*}$ & $4^{*}$ & $4^{*}$ & $4 *$ & $4 *$ & $4^{*}$ & $4 *$ & $4^{*}$ & $4^{*}$ & $4^{*}$ & $4^{*}$ & $4^{*}$ & $4^{*}$ & $4^{*}$ \\
\hline$\sum \mathrm{c}_{\mathrm{i}}$ & 160 & 160 & 160 & 160 & 160 & 160 & 160 & 160 & 160 & 160 & 160 & 160 & 160 & 160 & 160 & 160 & 160 & 160 & 160 & 160 \\
\hline VCM-HPP 6 & & & & & & & & & & & & & & & & & & & & \\
\hline$\#\left(c_{i}=40\right)$ & 3 & 3 & 3 & 2 & 1 & 1 & 0 & 0 & 1 & 0 & 0 & 0 & 0 & 0 & 0 & 1 & 0 & 0 & $0^{*}$ & 0 \\
\hline$\sum c_{i}$ & 150 & 140 & 130 & 80 & 60 & 40 & 10 & 30 & 40 & 30 & 20 & 10 & 10 & 10 & 30 & 40 & 10 & 10 & 0 & 10 \\
\hline VCM-HPP 7 & & & & & & & & & & & & & & & & & & & & \\
\hline$\#\left(c_{i}=40\right)$ & 3 & 2 & 2 & 2 & 2 & 2 & $0^{*}$ & 2 & 2 & $0 *$ & 1 & 1 & 1 & 1 & 1 & 1 & 2 & 2 & $0^{*}$ & 1 \\
\hline$\sum c_{i}$ & 120 & 80 & 80 & 80 & 80 & 80 & 0 & 80 & 80 & 0 & 40 & 40 & 40 & 40 & 40 & 40 & 80 & 80 & 0 & 40 \\
\hline VCM-HPP 8 & & & & & & & & & & & & & & & & & & & & \\
\hline$\#\left(c_{i}=40\right)$ & 2 & 3 & 2 & 3 & 2 & 2 & 2 & 2 & 2 & $0 *$ & 1 & 1 & 0 & 1 & $0 *$ & 1 & 0 & $0^{*}$ & $0^{*}$ & $0^{*}$ \\
\hline$\sum \mathrm{c}_{\mathrm{i}}$ & 100 & 130 & 110 & 130 & 90 & 80 & 90 & 90 & 80 & 0 & 40 & 40 & 30 & 40 & 0 & 40 & 20 & 0 & 0 & 0 \\
\hline VCM-HPP 9 & & & & & & & & & & & & & & & & & & & & \\
\hline$\#\left(c_{i}=40\right)$ & 0 & 1 & 0 & $0^{*}$ & 1 & 0 & 0 & $0^{*}$ & 0 & 0 & 1 & 1 & 0 & $0^{*}$ & 0 & 0 & $0^{*}$ & 1 & 0 & 1 \\
\hline$\sum \mathrm{c}_{\mathrm{i}}$ & 50 & 70 & 40 & 0 & 40 & 10 & 30 & 0 & 30 & 30 & 50 & 60 & 30 & 0 & 10 & 10 & 0 & 50 & 10 & 50 \\
\hline VCM-HI & & & & & & & & & & & & & & & & & & & & \\
\hline$\#\left(c_{i}=40\right)$ & 2 & 2 & $4^{*}$ & $4^{*}$ & $4 *$ & $4 *$ & $4 *$ & $4^{*}$ & $4^{*}$ & $4 *$ & $4^{*}$ & $4^{*}$ & $4 *$ & $4^{*}$ & $4 *$ & $4^{*}$ & $4^{*}$ & $4^{*}$ & $4^{*}$ & $4 *$ \\
\hline$\sum \mathrm{c}_{\mathrm{i}}$ & 130 & 90 & 160 & 160 & 160 & 160 & 160 & 160 & 160 & 160 & 160 & 160 & 160 & 160 & 160 & 160 & 160 & 160 & 160 & 160 \\
\hline VCM-HPP11 & & & & & & & & & & & & & & & & & & & & \\
\hline$\#\left(c_{i}=40\right)$ & 3 & 3 & 3 & 3 & 2 & 1 & 1 & 1 & 1 & 1 & $0 *$ & 1 & 1 & 1 & 2 & 1 & 2 & 0 & $0^{*}$ & $0^{*}$ \\
\hline$\sum \mathrm{c}_{\mathrm{i}}$ & 140 & 130 & 120 & 120 & 90 & 50 & 40 & 40 & 60 & 50 & 0 & 40 & 70 & 70 & 110 & 70 & 110 & 20 & 0 & 0 \\
\hline VCM-HPP12 & & & & & & & & & & & & & & & & & & & & \\
\hline$\#\left(c_{i}=40\right)$ & $4 *$ & $4^{*}$ & $4^{*}$ & $4^{*}$ & $4^{*}$ & $4 *$ & $4^{*}$ & $4^{*}$ & $4^{*}$ & $4 *$ & $4 *$ & $4 *$ & $4^{*}$ & $4^{*}$ & $4 *$ & $4 *$ & $4^{*}$ & $4^{*}$ & $4^{*}$ & $4^{*}$ \\
\hline$\sum \mathrm{c}_{\mathrm{i}}$ & 160 & 160 & 160 & 160 & 160 & 160 & 160 & 160 & 160 & 160 & 160 & 160 & 160 & 160 & 160 & 160 & 160 & 160 & 160 & 160 \\
\hline$\#\left(c_{i}=40\right)$ & 33 & 33 & 30 & 32 & 28 & 23 & 20 & 19 & 20 & 18 & 16 & 18 & 17 & 17 & 18 & 17 & 18 & 16 & 15 & 18 \\
\hline$\#\left(c_{i}=0\right)$ & 4 & 6 & 10 & 12 & 15 & 16 & 21 & 21 & 22 & 26 & 29 & 26 & 24 & 25 & 24 & 27 & 25 & 27 & 29 & 26 \\
\hline $\mathrm{C}_{\text {average }}$ & 130 & 123 & 112 & 111 & 99 & 90 & 77 & 74 & 73 & 68 & 57 & 65 & 68 & 64 & 68 & 63 & 69 & 60 & 56 & 65 \\
\hline$\#\left(\sum c_{i}=160\right)$ & 3 & 3 & 3 & 3 & 3 & 3 & 3 & 3 & 3 & 3 & 3 & 3 & 3 & 3 & 3 & 3 & 3 & 3 & 3 & 3 \\
\hline
\end{tabular}

*: (symmetric) equilibrium outcome 
Table 2. Data for the TS-VCM-HPP: price; individual contributions of total endowment; group contribution [0;160]; individual zero contributions; mean group contribution

\begin{tabular}{|c|c|c|c|c|c|c|c|c|c|c|c|c|c|c|c|c|c|c|c|c|}
\hline \multirow{3}{*}{$\begin{array}{r}\text { Experiment } \\
\text { TS-VCM-HPP 1 }\end{array}$} & \multicolumn{20}{|c|}{ Period } \\
\hline & 1 & 2 & 3 & 4 & 5 & 6 & 7 & 8 & 9 & 10 & 11 & 12 & 13 & 14 & 15 & 16 & 17 & 18 & 19 & 20 \\
\hline & & & & & & & & & & & & & & & & & & & & \\
\hline $\mathrm{p} 1$ & 62 & 76 & 95 & 100 & 95 & 100 & 100 & 100 & 95 & 95 & 95 & 95 & 95 & 95 & 100 & 95 & 96 & 98 & 97 & 72 \\
\hline$\#\left(c_{i}=40\right)$ & $4 *$ & $4 *$ & $4 *$ & 3 & $4 *$ & $4 *$ & $4 *$ & 3 & 3 & 3 & $4 *$ & $4 *$ & $4 *$ & $4 *$ & $4 *$ & 3 & 3 & 3 & 3 & 3 \\
\hline$\sum \mathrm{c}_{\mathrm{i}}$ & 160 & 160 & 160 & 120 & 160 & 160 & 160 & 120 & 120 & 120 & 160 & 160 & 160 & 160 & 160 & 120 & 120 & 130 & 130 & 150 \\
\hline TS-VCM-HPP 2 & & & & & & & & & & & & & & & & & & & & \\
\hline p2 & 76 & 96 & 100 & 100 & 95 & 100 & 100 & 93 & 100 & 95 & 95 & 95 & 95 & 95 & 95 & 95 & 95 & 100 & 95 & 95 \\
\hline$\#\left(c_{i}=40\right)$ & $4 *$ & $4 *$ & $4 *$ & $4 *$ & $4 *$ & $4 *$ & $4 *$ & $4 *$ & $4 *$ & 3 & 3 & $4 *$ & $4 *$ & $4 *$ & $4 *$ & $4 *$ & $4 *$ & $4 *$ & $4 *$ & $4 *$ \\
\hline$\sum \mathrm{c}_{\mathrm{i}}$ & 160 & 160 & 160 & 160 & 160 & 160 & 160 & 160 & 160 & 120 & 120 & 160 & 160 & 160 & 160 & 160 & 160 & 160 & 160 & 160 \\
\hline TS-VCM-HPP 3 & & & & & & & & & & & & & & & & & & & & \\
\hline p3 & 51 & 50 & 40 & 40 & 41 & 40 & 40 & 40 & 40 & 40 & 40 & 40 & 40 & 40 & 40 & 45 & 40 & 40 & 40 & 45 \\
\hline$\#\left(c_{i}=40\right)$ & 2 & 1 & 0 & 1 & 1 & $0 *$ & 1 & 1 & 2 & 2 & 1 & 1 & 1 & 0 & 2 & 3 & 3 & 2 & 3 & $4 *$ \\
\hline$\sum \mathrm{c}_{\mathrm{i}}$ & 90 & 40 & 20 & 40 & 40 & 0 & 40 & 40 & 80 & 80 & 40 & 40 & 40 & 10 & 80 & 120 & 120 & 80 & 120 & 160 \\
\hline TS-VCM-HPP 4 & & & & & & & & & & & & & & & & & & & & \\
\hline $\mathrm{p} 4$ & 40 & 40 & 46 & 45 & 45 & 56 & 67 & 77 & 80 & 92 & 95 & 98 & 95 & 100 & 100 & 95 & 100 & 100 & 95 & 100 \\
\hline$\#\left(c_{i}=40\right)$ & 3 & 2 & 2 & $4 *$ & $4 *$ & $4 *$ & $4 *$ & $4^{*}$ & $4 *$ & $4 *$ & $4 *$ & $4 *$ & $4 *$ & $4 *$ & $4 *$ & $4 *$ & $4 *$ & $4^{*}$ & $4 *$ & $4 *$ \\
\hline$\sum \mathrm{c}_{\mathrm{i}}$ & 120 & 80 & 80 & 160 & 160 & 160 & 160 & 160 & 160 & 160 & 160 & 160 & 160 & 160 & 160 & 160 & 160 & 160 & 160 & 160 \\
\hline TS-VCM-HPP 5 & & & & & & & & & & & & & & & & & & & & \\
\hline p5 & 51 & 76 & 97 & 100 & 100 & 89 & 99 & 87 & 98 & 98 & 99 & 97 & 99 & 98 & 98 & 99 & 98 & 99 & 99 & 98 \\
\hline$\#\left(c_{i}=40\right)$ & $4 *$ & $4 *$ & $4 *$ & $4 *$ & $4 *$ & 3 & 3 & $4 *$ & $4 *$ & $4 *$ & $4 *$ & $4 *$ & $4 *$ & $4 *$ & $4 *$ & $4 *$ & $4 *$ & $4 *$ & $4 *$ & $4 *$ \\
\hline$\sum \mathrm{c}_{\mathrm{i}}$ & 160 & 160 & 160 & 160 & 160 & 120 & 150 & 160 & 160 & 160 & 160 & 160 & 160 & 160 & 160 & 160 & 160 & 160 & 160 & 160 \\
\hline TS-VCM & & & & & & & & & & & & & & & & & & & & \\
\hline p6 & 81 & 91 & 98 & 97 & 100 & 100 & 99 & 99 & 95 & 97 & 99 & 98 & 99 & 99 & 99 & 100 & 99 & 99 & 99 & 95 \\
\hline$\#\left(c_{i}=40\right)$ & $4 *$ & $4 *$ & $4 *$ & $4 *$ & $4 *$ & $4 *$ & $4 *$ & 3 & $4 *$ & $4 *$ & $4 *$ & $4 *$ & $4 *$ & $4 *$ & $4 *$ & $4 *$ & $4 *$ & $4 *$ & $4 *$ & $4 *$ \\
\hline$\sum \mathrm{c}_{\mathrm{i}}$ & 160 & 160 & 160 & 160 & 160 & 160 & 160 & 120 & 160 & 160 & 160 & 160 & 160 & 160 & 160 & 160 & 160 & 160 & 160 & 160 \\
\hline TS-VCM-HPP 7 & & & & & & & & & & & & & & & & & & & & \\
\hline p7 & 43 & 65 & 91 & 100 & 99 & 99 & 100 & 78 & 98 & 99 & 90 & 96 & 92 & 95 & 95 & 96 & 90 & 86 & 56 & 56 \\
\hline$\#\left(c_{i}=40\right)$ & $4 *$ & $4 *$ & $4 *$ & $4 *$ & $4 *$ & $4 *$ & 3 & $4^{*}$ & $4 *$ & 3 & $4 *$ & 3 & $4 *$ & $4 *$ & $4 *$ & 3 & $4^{*}$ & 2 & $4 *$ & $4 *$ \\
\hline$\sum \mathrm{c}_{\mathrm{i}}$ & 160 & 160 & 160 & 160 & 160 & 160 & 120 & 160 & 160 & 120 & 160 & 120 & 160 & 160 & 160 & 120 & 160 & 80 & 160 & 160 \\
\hline TS-VCM-HPP 8 & & & & & & & & & & & & & & & & & & & & \\
\hline p8 & 97 & 81 & 94 & 81 & 65 & 62 & 96 & 92 & 93 & 56 & 53 & 85 & 36 & 63 & 88 & 51 & 75 & 99 & 100 & 100 \\
\hline$\#\left(c_{i}=40\right)$ & 2 & 3 & 1 & 3 & 2 & $4 *$ & 3 & 3 & 1 & 3 & 3 & 2 & 1 & $4 *$ & 3 & $4 *$ & $4^{*}$ & $4 *$ & $4 *$ & $4 *$ \\
\hline$\sum \mathrm{c}_{\mathrm{i}}$ & 90 & 150 & 90 & 150 & 90 & 160 & 130 & 140 & 60 & 120 & 120 & 90 & 40 & 160 & 150 & 160 & 160 & 160 & 160 & 160 \\
\hline TS-VCM-HPP 9 & & & & & & & & & & & & & & & & & & & & \\
\hline p9 & 99 & 94 & 99 & 100 & 95 & 98 & 99 & 99 & 70 & 99 & 99 & 53 & 99 & 99 & 99 & 99 & 99 & 54 & 97 & 91 \\
\hline$\#\left(c_{i}=40\right)$ & 3 & $4 *$ & 3 & 3 & $4 *$ & $4 *$ & $4 *$ & $4^{*}$ & $4 *$ & $4 *$ & $4 *$ & $4^{*}$ & $4 *$ & $4 *$ & $4 *$ & $4 *$ & 3 & $4 *$ & 3 & 3 \\
\hline$\sum \mathrm{c}_{\mathrm{i}}$ & 120 & 160 & 120 & 120 & 160 & 160 & 160 & 160 & 160 & 160 & 160 & 160 & 160 & 160 & 160 & 160 & 120 & 160 & 120 & 120 \\
\hline TS-VCM-HPP10 & & & & & & & & & & & & & & & & & & & & \\
\hline p10 & 46 & 40 & 45 & 40 & 53 & 91 & 96 & 99 & 89 & 97 & 96 & 98 & 84 & 99 & 96 & 99 & 95 & 99 & 99 & 97 \\
\hline$\#\left(c_{i}=40\right)$ & 2 & 1 & 2 & $4 *$ & $4 *$ & $4 *$ & $4 *$ & 3 & $4 *$ & $4 *$ & $4 *$ & $4 *$ & $4 *$ & $4 *$ & $4 *$ & $4 *$ & $4^{*}$ & $4 *$ & $4 *$ & $4 *$ \\
\hline$\sum \mathrm{c}_{\mathrm{i}}$ & 80 & 50 & 80 & 160 & 160 & 160 & 160 & 120 & 160 & 160 & 160 & 160 & 160 & 160 & 160 & 160 & 160 & 160 & 160 & 160 \\
\hline TS-VCM- & & & & & & & & & & & & & & & & & & & & \\
\hline p11 & 86 & 100 & 100 & 100 & 99 & 99 & 57 & 99 & 96 & 100 & 38 & 98 & 91 & 99 & 96 & 94 & 98 & 95 & 98 & 97 \\
\hline$\#\left(c_{i}=40\right)$ & $4 *$ & $4 *$ & $4^{*}$ & 3 & $4 *$ & $4 *$ & $4 *$ & $4^{*}$ & $4 *$ & 3 & $4 *$ & $4 *$ & $4 *$ & 3 & $4 *$ & $4 *$ & $4^{*}$ & $4 *$ & $4 *$ & $4 *$ \\
\hline$\sum \mathrm{c}_{\mathrm{i}}$ & 160 & 160 & 160 & 120 & 160 & 160 & 160 & 160 & 160 & 120 & 160 & 160 & 160 & 120 & 160 & 160 & 160 & 160 & 160 & 160 \\
\hline TS-VCM-HPP12 & & & & & & & & & & & & & & & & & & & & \\
\hline p12 & 46 & 40 & 45 & 45 & 40 & 40 & 40 & 40 & 40 & 40 & 40 & 40 & 40 & 40 & 40 & 40 & 40 & 40 & 40 & 40 \\
\hline$\#\left(c_{i}=40\right)$ & 1 & 2 & 1 & 1 & $0 *$ & 1 & 1 & $0^{*}$ & $0 *$ & 0 & $0 *$ & 0 & 1 & $0 *$ & $0 *$ & $0 *$ & $0^{*}$ & $0 *$ & $0 *$ & $0^{*}$ \\
\hline$\sum \mathrm{c}_{\mathrm{i}}$ & 80 & 80 & 40 & 50 & 0 & 50 & 40 & 0 & 0 & 10 & 0 & 10 & 50 & 0 & 0 & 0 & 0 & 0 & 0 & 0 \\
\hline$p_{\text {average }}$ & 65 & 71 & 79 & 79 & 77 & 81 & 83 & 84 & 83 & 84 & 78 & 83 & 80 & 85 & 87 & 84 & 85 & 84 & 85 & 82 \\
\hline$\#\left(c_{i}=40\right)$ & 37 & 37 & 33 & 38 & 39 & 40 & 39 & 37 & 38 & 37 & 39 & 38 & 39 & 39 & 41 & 41 & 41 & 39 & 41 & 42 \\
\hline$\#(\mathrm{ci}=0)$ & 7 & 9 & 11 & 8 & 8 & 7 & 7 & 10 & 9 & 10 & 9 & 8 & 8 & 8 & 6 & 7 & 7 & 8 & 6 & 5 \\
\hline $\mathrm{C}_{\text {average }}$ & 128 & 127 & 116 & 130 & 131 & 134 & 133 & 125 & 128 & 124 & 130 & 128 & 131 & 131 & 139 & 137 & 137 & 131 & 138 & 143 \\
\hline$\#\left(\sum c_{i}=160\right)$ & 6 & 7 & 6 & 6 & 9 & 9 & 7 & 6 & 8 & 5 & 8 & 8 & 9 & 9 & 9 & 8 & 8 & 8 & 8 & 9 \\
\hline
\end{tabular}




\section{APPENDIX II: Translated Instructions and Quiz}

\section{Instructions}

This experiment has been financed by the University of Arizona (EEUU), the Valencia Institute for Economic Research (IVIE) and the Valencia Regional Government. Its purpose is to study the way subjects behave in economic contexts and it will last for about 90 minutes. Your decisions will determine your monetary rewards at the end of the experiment in the way we will explain in a moment. You may make us any question raising your hand first. Any communication is strictly forbidden and it will be penalized with the immediate exclusion of the experiment.

Each participant has already won 500 pesetas just for been here. If you participate in the whole session you will be privately paid for your earnings at the end of the experiment.

We will briefly introduce the experiment dynamics right now. After our explanations, you will be asked to privately answer a simple questionnaire about the instructions to assess your level of comprehension. As this experimental session is designed for 16 participants we may ask you to leave the experiment if you make some mistake in the questionnaire. If the number of subjects with no wrong answers is greater than 16, the participants in the experimental session will be determined at random.

At the beginning of the experiment subjects are randomly assigned into two independent groups (so you all have the same probability of being members of each group). Once these two groups has been assembled, their composition will remain unchanged for the rest of the experiment.

This experiment lasts for 20 rounds, each of them divided into two stages: the First Stage and the Second Stage. We will begin with the explanation of the First Stage, to continue with the Second Stage thereafter, before we proceed with the questionnaire. If you pass the questionnaire, you will receive an initial endowment of 200 ECU (an Experimental Currency Unit) and you will immediately begin to participate in the 20 experimental rounds.

\section{The first stage}

Only four out of the eight members of each group will be allowed to participate in each second stage. Each round, an auction will be held during the first stage to determine which members will participate in the second stage. In the auction, all members of each group 
bid for the right to participate. As the computer will post ascending prices to access to the second stage, you just have to decide if you agree to pay the posted price to participate or if you prefer to leave the auction. If you leave the auction, you will have to wait until the round is over and you will get no profit in the round.

The computer will start with a posted price of $25 \mathrm{ECU}$ and it will increase the posted price by $5 \mathrm{ECU}$ as the auction goes on. Once three members of each group leaves the auction, or if the posted price is at least of $95 \mathrm{ECU}$, the price increases will be of 1 ECU. Auction will be over when just four subjects keep on it. The last posted price will be the price they will pay to participate in the second stage.

If after a price increase there are less than four subjects willing to pay the posted price, a random lottery will decide which of the subjects whom leave the auction in the last price increase will get into the second stage. In this case, the price subjects will pay to participate in the second stage will be the last posted price accepted by at least four subjects. If the computer reaches the maximum price of $100 \mathrm{ECU}$ and there are more than four subjects in the auction, a random lottery will determine which subjects will access the second stage.

An example: Take that the posted price is $55 \mathrm{ECU}$ and there are still seven subjects in the auction willing to pay this price to enter the second stage. As the price goes to 60, two of them leave the auction. As there are just five subjects in the auction, the price increases will be of 1 ECU. When the posted price goes from 64 to 65 ECU a subject decides to leave. The price paid by the remaining four subjects will be $65 \mathrm{ECU}$.

Take now that as price goes up to 65 ECU two subjects leave (so there are only three subjects in the auction): a random lottery will determine which of these two subjects will enter the second stage. The price paid by the four subjects to get into the second stage will be 64 ECU.

Meanwhile you are in the auction, you will get instant information about the price requested to enter the second stage and the number of subjects in the auction. At the end of each round all of you will get information about the price paid to enter the second stage.

\section{The Second Stage}

At the beginning of the second stage, the four remaining subjects will get an initial endowment of $40 \mathrm{ECU}$. Your decision in this stage will consist of allocating this $40 \mathrm{ECU}$ between two alternative funds: the Collective Fund and the Individual Fund. 
Each subject can allocate 00, 10, 20, 30 o 40 ECU to one fund. The rest of the initial endowment will automatically be allocated to the other. If you, say, allocate 10 ECU to the Collective Fund, the remaining 30 ECU will be allocated to the Individual Fund. Any allocation bigger than 40 ECU to any fund are not allowed.

\section{The Second Stage Profits}

Both Funds make profits. If you enter in the second stage your profits in the round will be the sum of the Individual Fund profits and the Collective Fund profits. Nevertheless, profits are not the same in both funds. For each ECU allocated to the Individual Fund you get a profit that only depends on your individual choice: for each ECU assigned to the individual fund you will get one ECU as return. The profit you will get for each ECU you assign to the collective fund depends not only on your choices but on the choices of the other three members of your group in the following way:

a) If the aggregate allocation to the Collective Fund of the four subjects is less than 160 ECU each of you will get a profit of 00 ECU.

b) If the aggregate allocation to the Collective Fund of the four subjects is $160 \mathrm{ECU}$ each of you will get a profit of $100 \mathrm{ECU}$.

You can check the profits you may get in the following table:

\begin{tabular}{|c|c|c|c|c|c|c|c|c|c|c|c|c|c|c|c|c|c|c|c|}
\hline \multicolumn{3}{|c|}{ Your choice } & \multicolumn{17}{|c|}{ The allocation to the collective fund of all four members of the group } \\
\hline 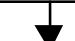 & $\downarrow$ & & & & & & & & & & & & & & & & & & \\
\hline$I F$ & $C F$ & 00 & 1 & & & 30 & 40 & \begin{tabular}{|l}
50 \\
\end{tabular} & 60 & 70 & \begin{tabular}{|l|l}
80 \\
\end{tabular} & \begin{tabular}{|l|l}
90 \\
\end{tabular} & \begin{tabular}{|l|l}
100 \\
\end{tabular} & 110 & 120 & 130 & \begin{tabular}{|l|l}
140 \\
\end{tabular} & $\mid 150$ & 160 \\
\hline 40 & 00 & 40 & 4 & & & 0 & 40 & 40 & 40 & 40 & 40 & 40 & 40 & 40 & 40 & -- & \begin{tabular}{|l}
-- \\
\end{tabular} & \begin{tabular}{|l}
- \\
\end{tabular} & \begin{tabular}{|l}
- \\
\end{tabular} \\
\hline 30 & 10 & -- & 30 & & & 0 & 30 & 30 & 30 & 30 & 30 & 30 & 30 & 30 & 30 & 30 & \begin{tabular}{|l}
-- \\
-1
\end{tabular} & - & - \\
\hline 20 & 20 & -- & -- & & & 0 & 20 & 20 & 20 & 20 & 20 & 20 & 20 & 20 & 20 & 20 & 20 & \begin{tabular}{|l}
-- \\
\end{tabular} & -- \\
\hline 10 & 30 & -- & -- & & & 0 & 10 & \begin{tabular}{|l|}
10 \\
\end{tabular} & \begin{tabular}{|l|}
10 \\
\end{tabular} & \begin{tabular}{|l|}
10 \\
\end{tabular} & \begin{tabular}{|l|}
10 \\
\end{tabular} & \begin{tabular}{|l|}
10 \\
\end{tabular} & \begin{tabular}{|l|}
10 \\
\end{tabular} & 10 & 10 & 10 & \begin{tabular}{|l|}
10 \\
\end{tabular} & \begin{tabular}{|l|l}
10 \\
\end{tabular} & \begin{tabular}{|l}
-- \\
\end{tabular} \\
\hline 00 & 40 & $\overline{--}$ & - & & & - & 0 & 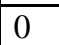 & \begin{tabular}{|l|}
0 \\
\end{tabular} & 0 & \begin{tabular}{|l|}
0 \\
\end{tabular} & \begin{tabular}{|l|}
0 \\
\end{tabular} & 0 & 0 & 0 & 0 & 0 & 0 & \begin{tabular}{|l|}
100 \\
\end{tabular} \\
\hline
\end{tabular}

\section{Your net profits}

At the end of each round you will get a net profit if you enter the second stage: the difference between the aggregate profits you get in the second stage minus the price you paid to enter the sateg in the auction. 
If you do not enter in the second stage in a round you do not get any profit, nor you pay any price, and your net profits are 0 .

If your profits in any second stage are smaller than the price you paid to enter the second stage you will get losses in the round. The losses will be cancelled with the profits collected in other rounds (including your initial endowment of 200 ECU). Your initial earnings of 500 pesetas you received for your assistance will never be involved.

Your accumulated profits will be automatically changed into pesetas at the end of the experiment at the exchange rate of $1 \mathrm{ECU}=8$ pesetas.

\section{Summary: The experimental sequence}

Questionnaire (16 subjects); Software explanation; Random matching of subjects between the two groups

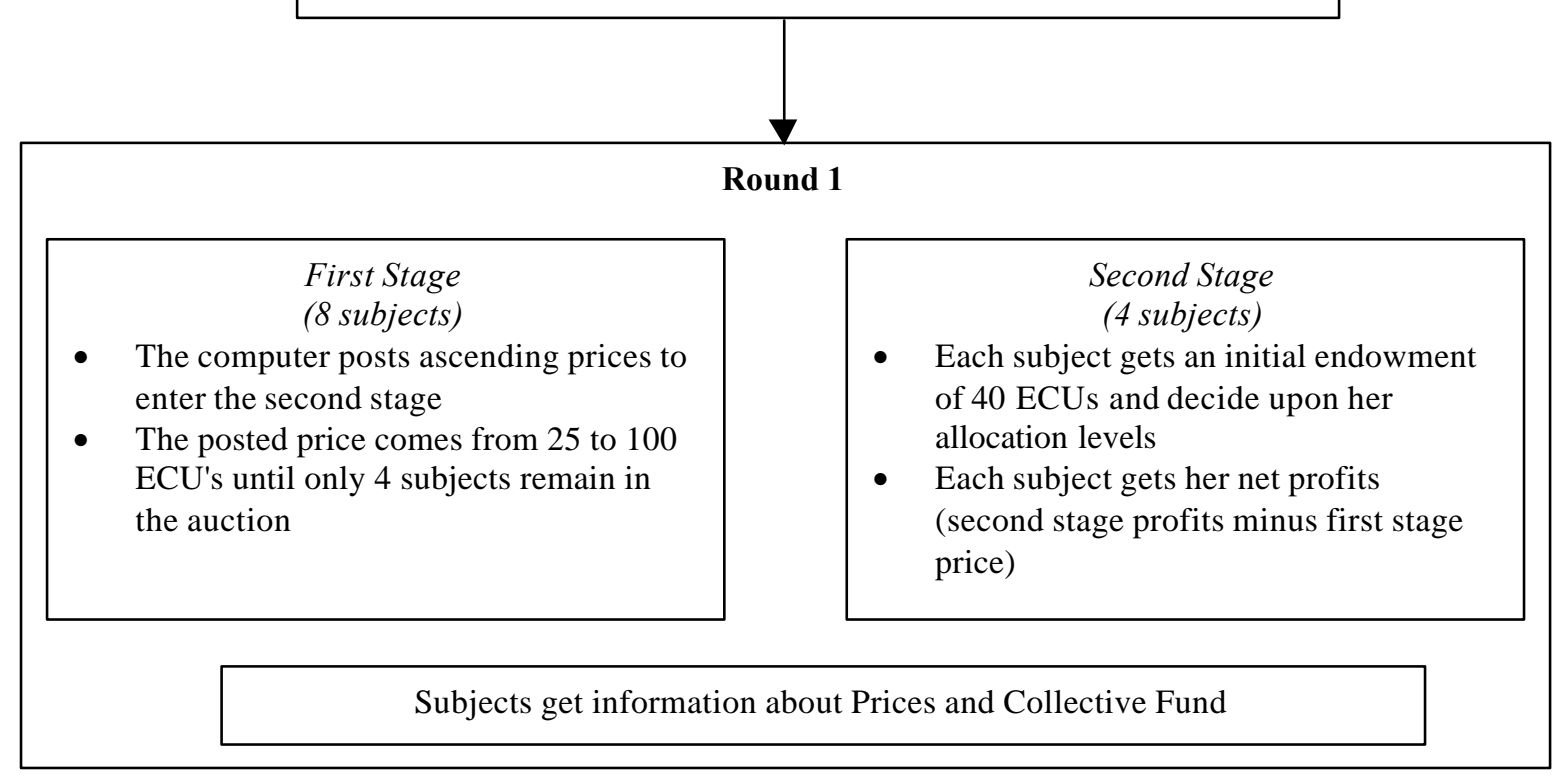




\section{Quiz}

1. If you allocate $30 \mathrm{ECU}$ to the Individual Fund, the amount of ECU you allocate to the Collective Fund will be:
a) 40 ECUS
b) 80 ECUS
c) 20 ECUS
d) 10 ECUS

2. If you allocate $20 \mathrm{ECU}$ to the Collective Fund, and all other subjects in your group allocate the aggregate amount of 10 ECUS to it, your individual profits from the Collective Fund will be:
a) 40 ECUS
b) 80 ECUS
c) 20 ECUS
d) 00 ECUS

3. If you allocate $10 \mathrm{ECU}$ to the Collective Fund, and all other subjects in your group allocate the aggregate amount of $50 \mathrm{ECU}$ to it, the total profits you get in this round will be:
a) 60 ECUS
b) 40 ECUS
c) 20 ECUS
d) 30 ECUS

4. If you allocate 30 ECU to the Individual Fund, the maximum feasible amount of ECU your group could allocate to the Collective Fund would be:
a) 150 ECUS
b) 130 ECUS
c) 80 ECUS
d) 40 ECUS

5. If you allocate $30 \mathrm{ECU}$ to the Collective Fund, the aggregate contribution of your group to the Collective Fund will be:
a) 120 ECUS
b) 90 ECUS
c) 80 ECUS
d) There is no enough information in the question to answer 


\section{APPENDIX III: Software Interface}

Figure 5. VCM-HPP and TS- VCM-HPP second-stage interface

\begin{tabular}{|l|l|l|l|l|l|}
\hline \multicolumn{7}{|c|}{ History } \\
\hline $\begin{array}{c}\text { Previous } \\
\text { Round }\end{array}$ & $\begin{array}{c}\text { Private Fund } \\
\text { ind. contribution }\end{array}$ & $\begin{array}{c}\text { Collective Fund } \\
\text { ind. contribution }\end{array}$ & $\begin{array}{c}\text { Collective } \\
\text { Fund } \\
\text { group contrib. }\end{array}$ & Round Profits & Total Profits \\
\hline$\ldots$ & $\ldots$ & $\ldots$ & $\ldots$ & $\ldots$ \\
\hline \\
\cline { 2 - 6 } & Private Fundind. contribution & $\ldots$ & $30 / 10$ & $40 / 0$ \\
\cline { 2 - 6 } & $0 / 40$ & $10 / 30$ & $20 / 20$ & Collective Fundind. contribution \\
\cline { 2 - 5 } & Information \\
\hline
\end{tabular}

Figure 6. TS- VCM-HPP first-stage interface

\begin{tabular}{|c|c|c|c|c|c|c|}
\hline \multicolumn{7}{|c|}{ History } \\
\hline Price & $\begin{array}{c}\text { Private Fund } \\
\text { ind. } \\
\text { contribution }\end{array}$ & $\begin{array}{c}\text { Collective Fund } \\
\text { ind. } \\
\text { contribution }\end{array}$ & $\begin{array}{c}\text { Collective } \\
\text { Fund } \\
\text { group contrib. }\end{array}$ & $\begin{array}{c}\text { 2nd Stage } \\
\text { Profits }\end{array}$ & $\begin{array}{c}\text { Net } \\
\text { Profits }\end{array}$ & $\begin{array}{c}\text { Total } \\
\text { Profits }\end{array}$ \\
\hline$\ldots$ & $\ldots$ & $\ldots$ & $\ldots$ & $\ldots$ & $\ldots$ & $\ldots$ \\
\hline & Current Price: & 35 & & No. of Bidders: & 8 & \\
\hline \multicolumn{7}{|c|}{ Posted Price } \\
\hline & 35 & & 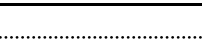 & 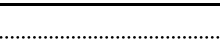 & . & 100 \\
\hline \multicolumn{7}{|c|}{ ¿Do you want to remain in the auction and pay the posted price? } \\
\hline & Remain & & $\begin{array}{l}\text { Seconds left } \\
\text { to make your } \\
\text { decision }\end{array}$ & 5 & & Exit \\
\hline \multicolumn{7}{|c|}{ Information } \\
\hline
\end{tabular}




\section{REFERENCES}

Abbink, Klaus and Abdolkarim Sadrieh (1995): "RatImage - Research assistance toolbox for computer-aided human behavior experiments", Discussion Paper B-325, University of Bonn.

Bagnoli, Mark and Michael McKee (1991): "Voluntary Contribution Games: Efficient Private Provision of Public Goods", Economic Inquiry, 29, 351-366.

Broseta, Bruno (2000): "Learning in experimental coordination games: An ARCH approach", Games and Economic Behavior, 24-50.

Cachon, Gerard and Colin Camerer (1996): "Loss avoidance and forward induction in experimental coordination games", Quarterly Journal of Economics, 111(1), 165-194.

Cadsby, Charles B. and Elizabeth Maynes (1999): "Voluntary provision of threshold public goods with continuous contributions: experimental evidence", Journal of Public Economics, 71, $53-$ 73.

Cooper, Russell W., Douglas V. DeJong, Robert Forsythe and Thomas W. Ross (1992a): "Communication in coordination games", Quarterly Journal of Economics, 107(3), 739-771.

Cooper, Russell W., Douglas V. DeJong, Robert Forsythe and Thomas W. Ross (1992b): "Forward induction in coordination games", Economic Letters, 40(2), 167-172.

Crawford, Vincent (1995): "Adaptive dynamics in coordination games", Econometrica 63(1), 103143.

Crawford, Vincent and Bruno Broseta (1998): "What price coordination? The efficiency-enhancing effect of auctioning the right to play", American Economic Review 88 (1), 198-225.

Croson, Rachel, and Melanie Marks (1999): "The Effect of Incomplete Information in a Threshold Public Goods Experiment", Public Choice, 99, 103-118

Croson, Rachel and Melanie Marks (2000): "Step Returns on Threshold Public Goods: A Meta- and Experimental Analysis", Experimental Economics, 2, 3, 239-259.

Davis, Douglas A. and Charles A. Holt (1993): Experimental Economics, Princeton University Press.

Isaac, Marc R., Kenneth F. McCue and Charles R. Plott (1985): "Public goods provision in an experimental environment", Journal of Public Economics 26, 51-74. 
Isaac, Marc R., James M. Walker and S. Thomas (1984): "Divergent Evidence on Free-Riding: An Experimental Examination of Possible Explanations", Public Choice, 43, 113-149.

Isaac, Marc R. and James M. Walker (1988): "Communication and free riding behavior: The voluntary contribution mechanism", Economic Inquiry 26(2): 585-608.

Isaac, Marc R., David Schmidtz and James M. Walker (1989): "The assurance problem in a laboratory market", Public Choice 62: 217-236.

Isaac, Marc R. and James M. Walker (1991): "Costly communication: An experiment in a nested public goods problem", in Laboratory research in political economy, T. Palfrey, editor, Ann Arbor: University of Michigan Press, 269-286.

Ledyard, John (1995): "Public Goods: A survey of Experimental Research", in John Kagel and Al Roth (eds.), Handbook of Experimental Economics, Princeton University Press.

Marks, Melanie, and Rachel Croson (1998): "Identifiability of Individual Contributions in a Threshold Public Goods Experiment", Journal of Mathematical Psychology, 42, 167-190

Van Huyck, John, Raymond Battalio and Richard Beil (1990): "Tacit coordination games, strategic uncertainty, and coordination failure", American Economic Review, 80, 234-248.

Van Huyck, John, Raymond Battalio and Richard Beil (1991): "Strategic uncertainty, equilibrium selection principles, and coordination failure in average opinion games", Quarterly Journal of Economics, 106, 885-911.

Van Huyck, John, Raymond Battalio and Richard Beil (1993): "Asset markets as an equilibrium selection mechanism: Coordination failure, game form auctions, and tacit communication", Games and Economic Behavior, 5(3), 485-504. 